\title{
Performance of novel dielectric barrier discharge reactor for biodiesel production from palm oil and ethanol
}

\author{
Sari Dafinah Ramadhani, Saphira Nurina Fakhri, and Setijo Bismo* \\ Universitas Indonesia, Faculty of Engineering, Department of Chemical Engineering, Kampus UI Depok, Depok 16424, \\ Indonesia
}

\begin{abstract}
The disadvantages of conventional biodiesel synthesis trigger the birth of new biodiesel synthesis methods using the DBD plasma reactor. The conventional methods with homogeneous and heterogeneous catalysts have significant constraints that the formation of glycerol compounds in large enough quantities that require considerable energy. The aim of present experiment is to design DBD non-thermal plasma reactor coaxial pipe type and to do its performance test in converting biodiesel The feed stock used are palm oil, ethanol, and argon gas as plasma carrier. Such a chemical reactor, this plasma reactor is also influenced by reaction kinetics and hydrodynamic factors. From this research, it can be seen that the optimum feed and gas flowrate being operated is 1.64 and $41.67 \mathrm{~mL} / \mathrm{s}$. The plasma reactor is used in the form of a quartz glass tube surrounded by a SS-314 spiral coil as an outer electrode. The applied operating conditions are 1 : 1 molar ratio of methanol/oil, ambient temperature of $28-30{ }^{\circ} \mathrm{C}$, and pressure 1 bar. From this performance test, it is found that this plasma reactor can be used to synthesize biodiesel from palm oil and methanol without catalyst, no formation of soap, and minimal byproducts.
\end{abstract}

\section{Introduction}

Indonesia's reliance on fossil energy has made domestic oil production decline drastically since 2001 ago. This situation is driven by the growing needs of the industrial sector in Indonesia. In the coming 2025 s, Indonesia is expected to experience a solar deficit of about 35 million kiloliters if no other energy source can replace it. [1] The decline in oil production encourages the development of alternative energy, one of which is biodiesel. In this case, biodiesel is chosen to be an alternative fuel because of the large amount of biodiesel feedstock available in Indonesia.

Biodiesel is defined as mono-alkyl esters of long chain fatty acids derived from renewable sources, primarily as triglyceride compounds in the form of vegetable oils and animal fats. Biodiesel can be renewed, easy to experience biodegradable (biodegradable), not toxic fuel, and environmentally friendly. Biodiesel combustion produces relatively lower emissions, has a high flash point, better lubrication, and high cetane numbers. The use of biodiesel has the potential to reduce the level of pollution and the likelihood of occurrence of carcinogenic compounds [2]. The raw materials used for biodiesel production may vary, depending on the geographical area and conditions of cultivation and availability. Indonesia is one of the largest palm oil producers in the world accompanied by Malaysia as the second largest producer of palm oil. Indonesia is predicted to grow rapidly, strengthening its position as the world's leading palm oil producer [3]. The total area of oil palm plantations in Indonesia is currently around 8 million hectares and is estimated to reach 13 million hectares by 2020 . Indonesia produces more than 23 million tons of palm oil by 2012 . [4]

The process of producing biodiesel from conventional vegetable oils (with homogeneous or acidic catalysts) has been successfully applied on a wide industrial scale. Synthesis of biodiesel is conventionally done by mixing palm oil, alcohol, and catalyst, then heated for several hours to produce transesterification reaction. The fundamental weakness in conventional methods (with homogeneous and heterogeneous catalysts) is that the formation of large amounts of glycerol compounds requires considerable energy for the heating process, requiring a long reaction time of about 1-8 hours, as well as at the end of the process of costing more and longer about 8-16 hours for separation and purification process []․ Furthermore, in biodiesel production carried out through traditional processes the amount of glycerol generated is equivalent to $10 \%$ of the biodiesel produced, and this negatively influences the national and international market for glycerin.

In this research will be examined the performance of DBD plasma reactor in making biodiesel. Dielectric barrier discharge (DBD) has been used to generate

Corresponding author: setijo.bismo@ui.ac.id 
plasmas for various applications, such as thin film deposition, surface treatment, ozone generation, pollution control and dissociation of gases. Dielectric barrier discharge plasma reactor uses two metal electrodes, separated by a dielectric material with a thickness of a few millimeters. When the electrodes are subjected to a high voltage difference on the order of kilovolts, an electrical discharge occurs between the electrodes and plasma is generated due to this dielectric gap between the electrodes. The main advantages of DBD plasma reactors are their ease of manufacturing, process control and operation, and being able to work at atmospheric pressure [6]. Basiccally, a plasma is an ionized gas, a gas into which sufficient energy is provided to free electrons from atoms or molecules and to allow both species, ions and electrons, to coexist. Dielectric barrier discharge reactor designed to synthesize biodiesel without the use of conventional catalysts.

The electro-catalysis system in this study is intended to utilize the high-energy electrons generated from the plasma as a catalyst in the biodiesel-forming reaction. These high-energy electrons are considered to act as catalysts as in conventional catalytic processes. These high-energy electrons can break chemical bonds (eg between $\mathrm{C}-\mathrm{H}, \mathrm{C}=\mathrm{O}$, etc.) depending on the energy content of the electrons. The application of electrocatalysis technology in the manufacture of biodiesel can be done at room temperature and atmospheric pressure because the plasma properties in the reaction are nonequilibrium plasma or non-thermal plasma where there is a significant temperature difference between electrons and neutral particles [7].

\section{Methodology}

\subsection{Raw material and preparation}

The raw material of triglyceride, commercial refine palm oil was purchased from local market (Tropicana), while techninal methanol were used as reactant. In this study, using high purity of argon as carrier gas of plasma

\subsection{Design and configuration of dielectric barrier discharge plasma reactor}

The design and configuration of the plasma reactor are of key importance as the success of synthesis is largely determined by the effective contact between high-energy electrons and the mixture of oil and methanol occurring in the plasma reactor. The length of contact time of electrons and reactants is also an important parameter because it is crucial to be what compounds will be produced by the process [5].

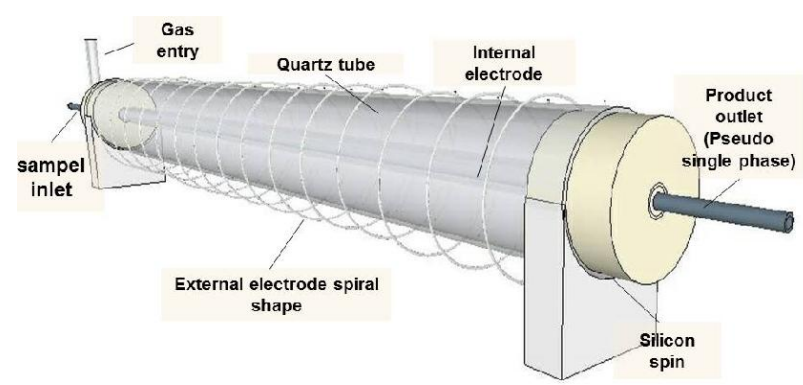

Fig. 1. Schematical design of DBD plasma reactor with cylindrical electrodes

Figure 1 shows Dielectric Barrier Discharge Plasma Reactor which has been designed and constructed. The electrode used is a cylinder configured. The total length of the reactor is $50 \mathrm{~cm}$. The spiral electrode is made of stainless steel (SS 316) wire with the number of rolls (N) 30 , while the inner diameter (ID) of the cylinder internal electrode (Ds) $30 \mathrm{~mm}$ stainless steel of $0.25 \mathrm{~mm}$ thickness (Ts) attached to the outer wall of the quartz tube as dielectric. DBDs configurations and principles are characterized by the presence of an insulating material in the discharge path. The insulting material in this research using quartz tube with ID $3 \mathrm{~cm}$ and length $30 \mathrm{~cm}$. Consideration of the selection of quartz materials due to the strong material to withstand high voltages and temperatures, facilitate installation, and facilitate visibility of the inside of the reactor if there will be damage to the component inside (due to transparent).

In the configuration of this plasma DBD reactor there is an area between the inner electrode and the outer electrode (spiral) is the main area of all its constituent atoms are split up into electrons and ions, which can move independently of each other. fom both electrodes colliding with the atoms and molecules derived from the flowed gas argon. . So that area is the peak area of the plasma reaction called the discharge gap. In this discharge gap occurs the conversion process from raw material palm and alcohol to biodiesel. This corona discharg is an electrical charge that looks like a thin, bluish violet light on the surface and close together when the voltage gradient reaches a critical value, caused by ionization occurring around the liquid and gas through the gap by high voltage. The location of the discharge gap is sketched in Fig 2.

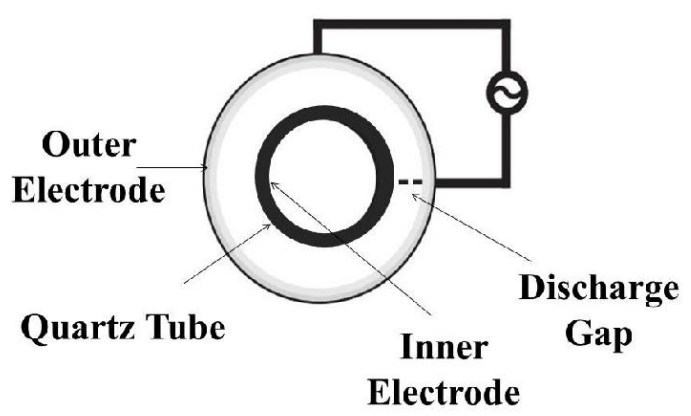

Fig. 2. Cross-section of plasma reactor 
Figure 3 belowing is the schematical equipment installation using for the experimental study.

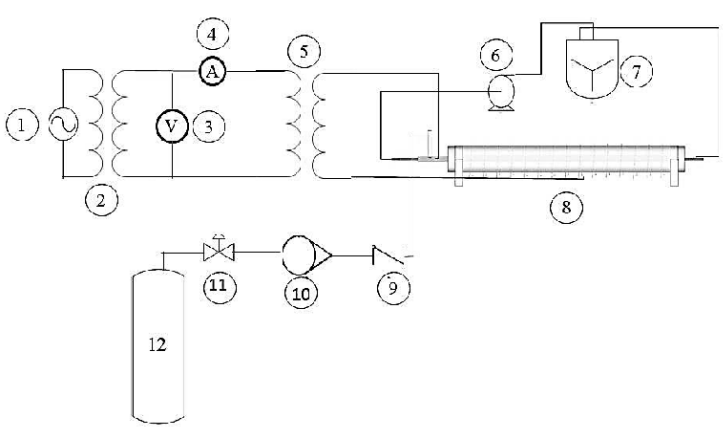

(1) electric sources (2) switch (3) slide regulator (4) multimeter (5) plasmatron (6) centrifuge pump (7) magnetic bar and stirrer (8)DBD Plasma Reactor (9) check valve (10) rotameter (11)gas regulator (12) argon gas

Fig. 3. Series of reactor systems and equipment

\subsection{Start-up reactor test}

After arranging all equipments as a system, it is necessary to test the start-up reactor of the tool to know the dielctric barrier discharge reactor performance and ensuring that the plasma generator system can be operated without any troubleshooting.

\subsubsection{Leak test}

Before the device start-up test, the reactor leak test was first performed. The reactor leak test is performed in a simple way by draining the aquadest and alcohol also air feed from the compressor into the reactor. If there is a leak then made reinstallation of a more uniform glue, or rubber installation, and prevent other leakage opportunities.

\subsubsection{Physical plasma test}

After ensure that reactor has not leaked, the next steps are physical plasma test. These steps is aim to look at the phenomenon emergence of plasma and determine the range of safe voltage conditions for the operation of the reactor. Before physical plasma test, the reactor must connected to the plasmatron.

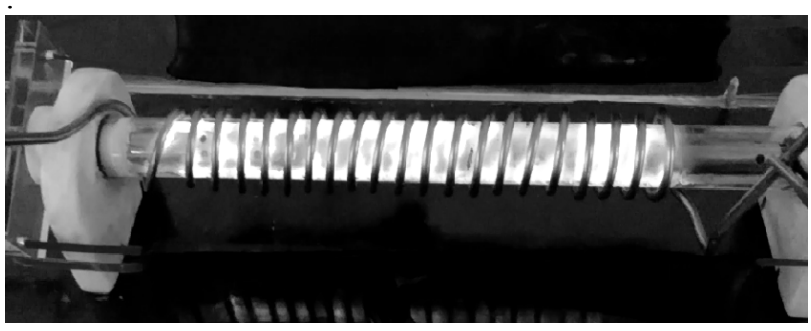

Fig. 4. Dielectric barrier discharge (DBD) reactor used in the experimental study.

Plasmatron used the experiment is the type of EPT (Electronic Power Transformer). Electronic Power
Transformer is a high voltage transformer that has a 10 $\mathrm{kV}$ secondary voltage at the transformer main voltage of 220 volts, has an output current of $30 \mathrm{~mA}$ at a $4 \mathrm{~A}$ input current and has an output frequency of $35 \mathrm{kHz}$ at an input frequency of $60 \mathrm{~Hz}$. The power required by EPT is very low, ie 68 Watt. Electricity used is alternating current (AC) from PLN with frequency $50 \mathrm{~Hz}$. The primary voltage on the EPT is measured using an aerial voltage transformer and measured through the amperemeter

\subsubsection{Hydrodinamic test}

One of the main requirements for high yield of biodiesel products $t$ is the exchange of argon gas with an efficient fluid intake in the DBD plasma reactor. It is important to obtain the superficial gas velocity $\left(\mathrm{U}_{\mathrm{G}}\right)$ and the optimal liquid feed rate $\left(\mathrm{U}_{\mathrm{L}}\right)$ for operating conditions at the DBD Plasma reactor. The determination of superficial gas velocity $\left(\mathrm{U}_{\mathrm{G}}\right)$ may correspond to the base derived from the hydrodynamic parameters [7]. The hydrodynamic parameters are very similar to the fluid flow. The flow pattern of the DBD reactor is assumed to approach the flow pattern of plugflow. The phase occurring in the DBD reactor is a single pseudo phase which is assumed that both phases are mixed homogeneously. This flow regime is considered to be very diverse and has a high amount of reynolds. Single-phase pseudo flow is simpler than two phase streams. Because the two-phase flow has various possible flow regimes, phase distribution and so on. In the hydrodinamic test, palm oil and ethanol is used as the reactant liquids.

The gas used is the air adequately coming from the compressor. Operating conditions are gas flow rates between $0.5-2.5 \mathrm{~L} / \mathrm{min}(8.3-41.7 \mathrm{~mL} / \mathrm{s})$, operated at atmospheric pressure and room temperature $\left(29^{\circ} \mathrm{C}\right)$ while the power supply for peristaltic pump varies between 5-7 volts (DC),

\subsection{Biodiesel production process}

The biodiesel synthesis reaction is carried out by feeding palm oil and ethanol at ambient temperature and pressure, and feed rate of $1.64 \mathrm{ml} / \mathrm{s}$, controlled through centrifugal pump power supply and gas flow rate of 2.5 Liter/min as measured by rotameter flowmeter and calibrated with bubble soap columns. The regulator slide voltage is set at 220 Volts and the molar ratio between oil and alcohol is 1: 1 . The reaction does not require a catalyst and is carried out for 6 hours at 15 minutes every hour. The reactor product or output is measured in concentration with GC-FAME and GC Glycerol and its functional group are known from FTIR.

\section{Results and discussion}

\subsection{Hydrodinamic Test}

\subsubsection{Calibration between power suppy pump and flow rate product}


The graph below (Fig 4) shows relationship between power supply of pump and product flowrate. From this graph, we can know the flowrate of product that is assumed to be the same as the liquid feed flow rate. The relationship between the power supply pump and the product output is denoted by $y=0.008 x+0.0503$. For 5 -7 volt is equal to $1.505-1.77 \mathrm{ml} / \mathrm{s}$. The higher the power supply voltage applied to the centrifugal pump will increase the flow rate of the product. Centrifugal pumps are used to transport fluids by the conversion of rotational kinetic energy to the hydrodynamic energy of the fluid flow.

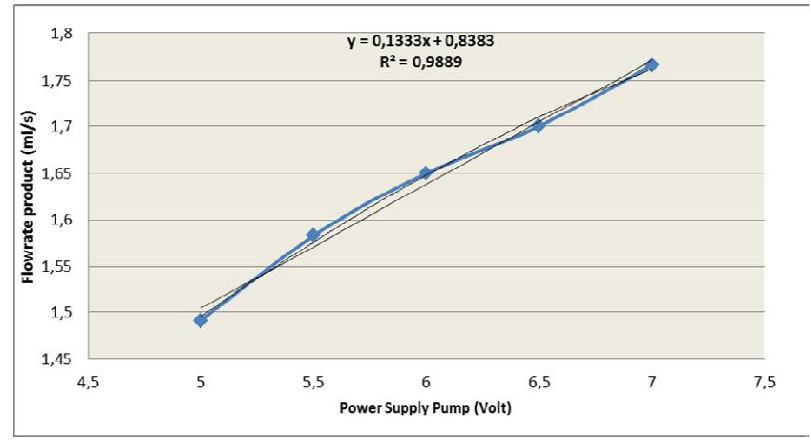

Fig. 5. Curve calibration between power suppy pump and flow rate product

\subsubsection{Effect of feed flowrate on product flowrate with variations of gas flowrate}

From this graph (Fig 6), it can be seen that the product flow rate assumed as the lowest single pseudo phase $(1.22 \mathrm{ml} / \mathrm{sec})$ is at the lowest liquid feed rate $(1.50 \mathrm{ml} /$ s) and the highest gas flow rate $(41.67 \mathrm{ml} / \mathrm{sec})$. While the product flow rate value is assumed to be the highest single pseudo phase $(1.70 \mathrm{ml} / \mathrm{s})$ at the highest liquid feed flow rate $(1.77 \mathrm{ml} / \mathrm{s})$ and the lowest gas flow rate $(8.34 \mathrm{ml} / \mathrm{s})$. So the flow rate product will increase along with the increase of the liquid feed flow rate, but will decrease along with the high gas flow rate. From this graph it can also be seen that the liquid feed flow rate has greater effect on the product flow rate than the gas flow rate. It turns out that gas can hold the liquid longer in the reactor thus making the liquid more durable in flowing. This retained gas is a potential gas for mass transfer with liquid feed. For that in this hydrodynamic process, the purpose of its operation is to make the gas more controlled so as to optimize mass transfer process [8]. To obtain much of the remaining gas, a maximum gas flow rate of $41.67 \mathrm{ml} / \mathrm{s}$ is chosen. The most optimal operating flux feed flow conditions are at the most stable (smallest deviation). The point is $1.64 \mathrm{~mL} / \mathrm{s}$ which for each variation of the gas flow rate produce the most constant value of the product flow rate with a greater difference of less than 0.1 . The liquid flow rate rating of $1.64 \mathrm{~mL} / \mathrm{s}$ is obtained by adjusting the 6 volt power supply.

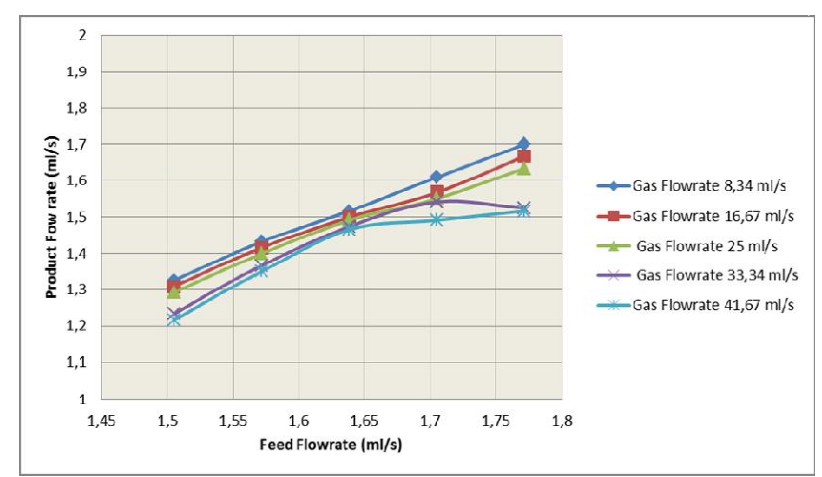

Fig. 6. Effect of feed flowrate on product flowrate with variations of gas flowrate

\subsubsection{Effect of Feed Flowrate on Space Time with Variations of Gas Flowrate}

With long residence time, the contact time between the feed gas and the raised plasma will be longer so that more reactions occur. The reactants must be in the reactor plasma for a long time to complete the reaction or in other words, a long enough time to stay in order for the reaction to proceed properly [9]. Therefore, in this way it is expected to have a sufficiently long residence time for the reaction to take place so that the conversion occurs even larger. The calculation of residence time is shown in Formula 1 below.

$$
t=V / Q_{L}
$$

Where $\mathrm{t}$ is space time (second), $\mathrm{V}$ is volume reactor which $53 \mathrm{ml}$, and $\mathrm{Q}_{\mathrm{L}}$ is liquid feed flow rate $(\mathrm{ml} / \mathrm{sec})$.

Table 1. Average residence times for various gas phases and liquid phase flow rates

\begin{tabular}{|c|c|c|c|c|c|}
\hline \multirow{2}{*}{$\begin{array}{c}\mathrm{Q}_{\mathrm{L}} \\
(\mathrm{ml} / \mathrm{s})\end{array}$} & \multicolumn{6}{|c|}{ Residence time $(\mathrm{s})$} \\
\cline { 2 - 6 } & $\begin{array}{c}\mathrm{Q}_{\mathrm{G}}= \\
8.34 \\
\mathrm{ml} / \mathrm{s}\end{array}$ & $\begin{array}{c}\mathrm{Q}_{\mathrm{G}}= \\
16.67 \\
\mathrm{ml} / \mathrm{s}\end{array}$ & $\begin{array}{c}\mathrm{Q}_{\mathrm{G}}= \\
25 \mathrm{ml} / \mathrm{s}\end{array}$ & $\begin{array}{c}\mathrm{Q}_{\mathrm{G}}= \\
33.34 \\
\mathrm{ml} / \mathrm{s}\end{array}$ & $\begin{array}{c}\mathrm{Q}_{\mathrm{G}}= \\
\begin{array}{c}11.67 \\
\mathrm{ml} / \mathrm{s}\end{array}\end{array}$ \\
\hline 1.51 & 40.03 & 40.54 & 41.06 & 43.00 & 43.59 \\
\hline 1.57 & 37.00 & 37.44 & 37.88 & 38.81 & 39.29 \\
\hline 1.64 & 34.97 & 35.36 & 35.55 & 35.96 & 36.16 \\
\hline 1.71 & 32.98 & 33.85 & 34.22 & 34.40 & 35.55 \\
\hline 1.77 & 31.20 & 31.82 & 32.47 & 34.78 & 34.97 \\
\hline
\end{tabular}

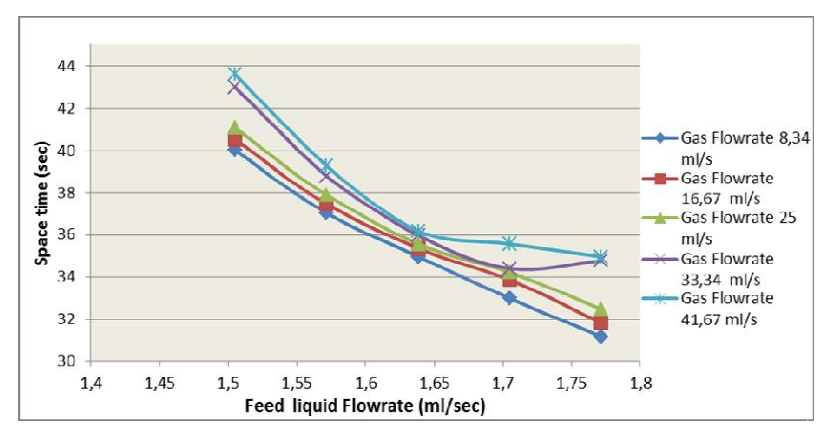

Fig. 7. Effect of Feed Flowrate on Space Time with Variations of Gas Flowrate 
From Fig 7, we know that the decrease of fluid residence time in the reactor due to gas phase flow is highly significant at low fluid flow rate and high fluid flow rate. This is indicated by very low fluid flow rate (1.505 $1.57 \mathrm{ml} / \mathrm{s}$ ), flow regime in low interaction regime, so that the liquid phase pressure is not strong enough to withstand the gas phase pressure, so the residence time is strongly influenced by the gas phase. At a very high flow rate $(1.705-1.77 \mathrm{ml} / \mathrm{s})$, the flow regime in the interaction regime is high, so the liquid phase pressure is strong enough, but at very high flow rates creates an unstable regime and is unable to withstand gas phase pressures, so the residence time is strongly influenced by the gas phase. While at a flow rate of $1.64 \mathrm{ml} / \mathrm{s}$, the gas phase effect is less significant with decreasing residence time. This may be due to the flow rate of 1.64 $\mathrm{ml} / \mathrm{s}$ of the regime flow in the high interaction regime so that the liquid phase pressure is strong enough and stable to withstand the gas phase pressure so that the residence time is less affected by the gas phase. Thus, based on this initial hydrodynamic test, it is predicted that the most optimum feed flow and gas flow rate to be operated in Non-Thermal DBD plasma reactors is 1.64 $\mathrm{ml} / \mathrm{s}$ and $41.67 \mathrm{ml} / \mathrm{s}$.

\subsection{Methyl ester (biodiesel) production}

After the reaction process with the operation conditions that have been mentioned in methodology, fatty acid methyl ester is produced incresing the time reaction. The product is analyzed by FTIR, GC FAME, and GC Glicerol. FTIR is analysis to observe chemical properties, whereas GC-FAME to find out \% fatty acid methyl esters formed and GC-Glicerol is to know \% Glicerol that is formed. The first thing to do is qualitive analysis using FTIR. The proven probability of functional group of FAME seen in Figure 8.

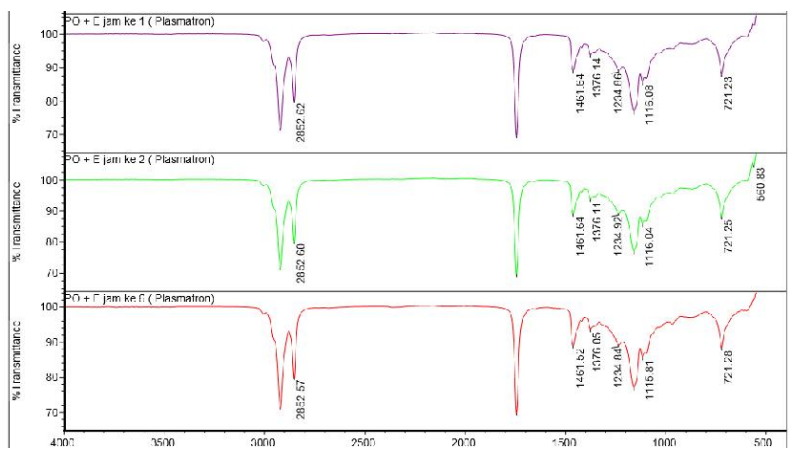

Fig. 8. FTIR biodiesel test results from hours 1, 2, and 6

The change of number waves detected in FTIR results shows that not significant. However, until 6 hours has not been detected the wave number in region 1428$1446 \mathrm{~cm}^{-1}$ which is the functional group of methyl ester $\left(-\mathrm{O}-\mathrm{CH}_{3}\right)$. It means that the reaction process until 6 hours is still continues and the process produced FAME in a low content so can not detect that absorption area. However, the purpose of this study is just to confirm and ensure that reactor plasma DBD can converting palm oil into biodiesel, although still in small quantities. To prove the FTIR test result, there will be GC FAME test to know how many \% FAME contained in a product. From GC FAME result, \% FAME formed are 7,8 with \% Glicerol formed are $0,098 \%$

\section{Conclusions}

Based on the results of the research, it is possible to produce biodiesel from palm oil and methanol using the design DBD plasma reactor, ie DBD plasma reactor with total length about $30 \mathrm{~cm}$ with fluid flowrate of $1.64 \mathrm{~mL} / \mathrm{s}$ (equal with 6 volt) and a gas carrier gas flowrate of $41.64 \mathrm{~mL} / \mathrm{s}$, based on the hydrodynamic test performed. Based on the results of this study, it is possible to produce biodiesel from palm oil using corona discharge plasma reactor technology. In this resreach, the method of gas chromatography (GC-FAME) and FTIR are used to identify the formation of methyl esters homologue from fatty acids (FAME). The study has also well demonstrated one of main advantage of this process, that is methyl being obtained without chemical catalyst and without the formation of glycerin byproduct. This means that plasma discharge in the form of corona may be a promising technology, because it clearly does not require any catalyst and the formation of a byproduct does not occur as well.

This research has been funded thanks to "PITTA Grant" (Hibah Publikasi Internasional Terindeks Tugas Akhir Mahasiswa Universitas Indonesia) 2018 from Directorate Research and Community Service Universitas Indonesia. The authors declare no competing interests or any conflicts of financial interests.

\section{References}

1. 1.Kholiq, I., Analisis Pemanfaatan Sumber Daya Energi Alternatif Sebagai Energi Terbarukan untuk Mendukung Subtitusi BBM. Jurnal IPTEK. 19(2): p. 75-91. (2015).

2. 2.Hassan, M.H. and M.A. Kalam, An overview of biofuel as a renewable energy source: development and challenges. Procedia Engineering.. 56: p. 3953.(2013)

3. 3.Ermawati, T. and Y. Saptia, Kinerja Ekspor Minyak Kelapa Sawit Indonesia The Export Performance of Indonesia 's Palm Oil. Buletin Ilmiah Litbang Perdagangan. 7(2): p. 129-148.(2013)

4. 4. Herianto, D.D., Analisis Dayasaing Industri CPO Indonesia di Pasar Internasional. (2008).

5. 5. Yudhistira, A.D. and I. Istadi, Unjuk Kerja Reaktor Plasma Dielectric Barrier Discharge untuk Produksi Biodiesel dari Minyak Kelapa Sawit. Teknik.. 34(2): p. 116-122. (2013)

6. 6. Winanti, W.S., Purwanto, W.W., Bismo, S., 2014. Decomposition of Carbon Dioxide in the Three-pass Flow Dielectric Barrier Discharge Plasma Reactor. International Journal of Technology. Volume 5(1), pp. 51-59 (2013)

7. 7.Istadi, I., et al., Electro-Catalysis System for Biodiesel Synthesis from Palm Oil over Dielectric- 
Barrier Discharge Plasma Reactor. Bulletin of Chemical Reaction Engineering \& Catalysis.. 9(2).(2014).

8. 8. Husodo, F., Model Pola Alir Fasa Cair Dalam Reaktor Trickle Bed Dengan Packing Karbon Aktif. Reaktor. 9(2): p. 73-78.(2017)

9. 9. Wang, Q., et al., Investigation of dry reforming of methane in a dielectric barrier discharge reactor. Plasma Chemistry and Plasma Processing. 29(3): p. 217-228.(2009)

10. Ani, F.N., Said, N.H., Said, M.F.M., Optimization of Biodiesel Production using a Stirred Packed-bed Reactor. IJTech. 9(2), 219-228 (2018) 